\title{
Collective digital dependence of employees and the perspective of leaders
}

\author{
Lucio Lage Gonçalves ${ }^{1 \star}$, Antonio Egidio Nardi ${ }^{2}$, Hugo Kegler dos Santos ${ }^{3}$, Douglas Rodrigues ${ }^{4}$, Anna Lucia Spear King \\ ${ }^{1}$ Conscious Use of Technologies, Institute of Psychiatry (IPUB). Federal \\ University of Rio de Janeiro (UFRJ), Rio de Janeiro, Brazil. \\ ${ }^{2}$ Department of Statistics, Institute of Mathematics and Statistics, \\ Fluminense Federal University (UFF), Rio de Janeiro, Brazil. \\ ${ }^{*}$ Corresponding author \\ Lucio Lage Gonçalves, Vice Presidente José Alencar, 1500, block 1, apt 1004 \\ Barra da Tijuca - Rio de Janeiro / RJ - CEP 22775 - 033. \\ Delete - Conscious Use of Technologies, Institute of Psychiatry (IPUB). \\ Federal University of Rio de Janeiro (UFRJ), Rio de Janeiro, Brazil. \\ Department of Statistics, Institute of Mathematics and Statistics, Fluminense \\ Federal University (UFF), Rio de Janeiro, Brazil. \\ Submitted: 03 Aug 2020; Accepted: 10 Aug 2020; Published: 19 Aug 2020
}

\begin{abstract}
Summary
Introduction: Human behavior has been changing due to digital technologies and the mobility provided by the integration of the Internet with mobile phones, causing diverse dependences. Organizational collective environments already have symptoms of these dependences.
\end{abstract}

Objective: To evaluate, in an unusual way, the digital dependence of employees, the perception of leaders regarding employee dependence and to compare results between the two groups.

\begin{abstract}
Method: Volunteers were informed about the scope of the research. On line data collection started between 03/01 and 04/15/19. The sample had 330 employees with no management positions that answered to the Digital Employee Dependence Scale -EDDE and 96 with leadership positions that answered to the Scale to Evaluate Leaders'Perception of Digital Dependence Employees - EPLDDE, generating two databases for the analysis.
\end{abstract}

Results: Presented separately, employee and leaders, with percentage by option of answers that indicate low perception of the volunteers on the subject. Convergences and divergences between leaders and employees reinforce possibles unevennesses of knowledge about this subject.

Discussion: Three blocks: (a) EDDE; (b) EPLDDE; (c) comparative EDDEx EPLDDE. Highlighting of the convergences and divergences between visions of leaders and employees on similar questions signaling the need for analysis of these differentiated perceptions. Conclusion: There is no general concern of leaders and employees about digital dependence in the organization, although there are signs of existence. There are divergences between them about various elementary aspects of this theme. It is necessary guide them on the characteristics of digital dependence to better understand and correct their digital practices.

Keywords: Digital Dependence of Employees; Leaders' Perception of Digital Dependence; Digital Dependence On Organizations; Edde Scale; Epldde Scale.

\section{Introduction}

Digital dependence is the lack of autonomy to perform tasks without digital communication devices in general such as Internet, handsets, tablets, social networks and others (Gonçalves, 2017). It includes manifestations such as alienation, anxiety, fear and insecurity, preventing theindividual from performing his or her activities normally, and may also interfere in the group of people living with them, such as family, work and other groups. Nomofobia is an example of this and it means the fear that the pathological dependent of technology must be unable to use it $[1,2]$.
These new behaviors derived from digital practices are transformative on a collective scale as [3] affirm about the process of global change associated with the social, technological and time-to-use of these technologies is changing social practices as well as creating new ones. These changes pointed out by [3] have been observed since the mid-1990s when this theme aroused interest and, with new technological resources emerging, human behavior has been transformed, including uncontrolled use that can cause damage to physical and psychological health, not only caused by the use of the internet. In addition to the dependence of the Internet as it has been studied previously, the dependence on social networks and communication applications has also been researched [4]. 
All this scenario of Internet, social networks and celular phones, is not limited to individual situations constituting a social phenomenon, given its collective characteristic, influencing organizational environments, until now not contemplated [5].

Excessive, indiscriminate use and for many consecutive hours by employees at work can adversely affect individual performance, organizational results, and the personal life of individuals, beyond collective behavior.

As collective human behavior interferes with organizational culture, digital habits in organizations can influence this culture, which is as influential in human behavior and in organizations as it is invisible and, paradoxical as it may be, is strong enough to forge the organizational profile [6].

The objective of this research was to evaluate the digital dependence of employees who do not hold management positions, the perception of leaders on the digital dependence of these employees and to compare results of the two groups in the Ministry of Agriculture, Livestock and Supply, (MALS) in Brasilia city, Federal District of Brasil. The visions collected (employees and leaders) are important because of their different perspectives for the same type of questions

\section{Method}

The keyword searched in MeSH - Medical Subject Headings did not find terms that express these contents. Due to the unprecedented nature of this theme in organizations, key words were created that revealed the essence of the theme. Prior to the application of the research, the Social Communications area of the organ searched communicated to the employees and leaders what the research was and its subject, besides the conditions of access and that the data would be treated collectively, ensuring the confidentiality of the answers.

The two statistically validated scales were applied on line, simultaneously, from $03 / 01 / 2019$ to $04 / 15 / 2019$, with a final sample of 330 volunteers with no management positions and 96 leader's volunteers (with management positions) of both sexes with ages between 18 to 65 years. The electronic data collection used a computational resource from the Ministry of Agriculture, Livestock and Supply (MALS), generating two separated databases for employees and leaders, from which results were tabulated, extracted percentage from the answers, analysis, discussion and conclusions.

The data analysis of the answers was done by question, of the two scales according to tables 1 and 2 and analyzed separately, ending with a comparison between them. It was held between 04/16/2019 and $05 / 15 / 2019$. The percentages obtained from each question by answer option (never, rarely, frequently and always) were extracted to know the opinions of the volunteers about each one of them allowing to know their digital practices. For factor analysis we used the software [7].

The EDDE scale has 19 questions with options: Never/Rarely (0), Frequently (1) and Always (2) to check the frequency of use of digital technologies by employees in an organizational environment and the EPLDDE scale has 17 questions and the same options of the EDDE.

The limitations to the application of the research were derived from bureaucratic and normative aspects of the organ searched and did not influence the results.

\section{Inclusion Criteria}

For the EPLDDE survey, it was necessary to have a management position and for the EDDE not to hold these positions and to be active in the functions.

\section{Exclusion Criteria}

Volunteers with positions of leadership for EDDE and without positions of leadership for the EPLDDE.

\section{Results}

\section{Descriptive Statistics}

Results obtained from demographic data showed adequacy to what was requested as reported in the Discussion section. Errors in data filling by volunteers generated elimination of questionnaires answered, ending the sample in 330 employees, being 216 men $(65.5 \%)$ and 114 women $(34.5 \%)$. The predominant age group was 31- 40 years old with 95 employees (29\%). Higher education and specialization predominated with $189(57.2 \%)$. About 96 leaders, 58 are men $(60.4 \%)$ and 38 women (39.6\%). The predominant age group among leaders was between $41-50$ years old with about $30 \%$ of leaders. The prevalent degrees of education are higher education and specialization with (63\%). The results are presented by scale, with analysis in the Discussion section.

\section{Factor Analysis (Fa)}

The same Factor Analysis was performed for both result sets (EDDE and EPLDDE Scale). The first test was Bartlett's Sphericity test to see if the variables are correlated with each other and in both cases the results pointed to a non-covariance matrix. equal to identity. The next test was to verify the suitability of AF by KMO (Kaiser - Meyer - Olkin) having found a value of 0.79363 for EDDE and 0.78141 for EPLDDE, values very close to 0.8 and considered good according to $[8,9]$.

Due to the results found in the Bartlett and KMO tests, it was appropriate to perform the AF, and the factor loads were verified using the Factor Loads, Screeplot and Parallel Analysis criteria. The most appropriate results for both EDDE and EPLDDE were by Screeplot that indicated the total of 5 factors in both scales. Finally, Cronbach's Alpha was calculated to measure the internal consistency of the scale, and found 0.7790 for EDDE and 0.8460 for EPLDDE, indicating satisfactory consistency [10].

\section{Results Overview}

Emphasis is placed on the low level of concern of employees regarding restrictions on the use of their digital media in service, as well as the total adherence to the use of their own media in service. Additionally, they believe that the overuse of their digital devices does not detract from their performance and, on the 
contrary, aid in good relationship with their colleagues. Employees are reassured about the freedom granted by the organization to use their digital devices, including for work purposes, which is reflected in the results.

The results of the leader's point to a general context where there is no concern with the digital practices of their employees regarding indiscriminate use at work, nor with the labor legislation due to problems with hours in service out of the work, through the cellular devices, without the due remuneration. The high results percentages on various issues, reveals leaders' naturalness about the organization's current digital practices.
Tables 1 (EDDE) and 2 (EPLDDE) below present the percentage results by response options (N, R, F and A) that allowed the percentage statistical analysis of the prevalence of the volunteers' choices. Percentage results by answer option and by item - EDDE scale The acronym CTCTO, in all questions, means the set of technological devices (computer, cell phone, tablet and others).

Answer Options:

$\mathrm{N}($ Never $)=0 ; \mathrm{R}($ Rarely $)=0 ; \mathrm{F}($ Frequently $)=1 ; \mathrm{A}($ Always $)=2$

Table 1: Percentage results by response option and by item - EDDE scale.

\begin{tabular}{|c|c|c|c|c|c|}
\hline S. No. & Questions & $\mathbf{N}$ & $\mathbf{R}$ & $\mathbf{F}$ & A \\
\hline 1. & How often do you feel destabilized when CTCTO access restrictions are imposed on the organization? & $21,2 \%$ & $52,4 \%$ & $21,5 \%$ & $4,8 \%$ \\
\hline 2. & $\begin{array}{l}\text { How often do you prioritize your personal communication (Facebook, WhatsApp, e.mail, etc...) taking more } \\
\text { time with your CTCTO than with work? }\end{array}$ & $32,7 \%$ & $56,7 \%$ & $9,1 \%$ & $1,5 \%$ \\
\hline J. & How often has your work performance been affected by the overuse of CTCTO technologies inthe organization? & $40,9 \%$ & & $9,1 \%$ & \\
\hline 4. & How c & $33,0 \%$ & $50,6 \%$ & $12,7 \%$ & $3,6 \%$ \\
\hline 5. & $\begin{array}{l}\text { How often do you feel uneasy because there areactions to minimize CTCTO digital dependency in the } \\
\text { organization? }\end{array}$ & $50,6 \%$ & $39,7 \%$ & $6,4 \%$ & $3,3 \%$ \\
\hline 6. & How often do you see unconcern with the CTCTODigital Dependency in the organization? & $14,8 \%$ & $38,8 \%$ & $36,7 \%$ & $9,7 \%$ \\
\hline 7. & How o & $16,4 \%$ & $37,0 \%$ & $36,4 \%$ & $10,3 \%$ \\
\hline 8. & $\begin{array}{l}\text { How o } \\
\text { CTCT }\end{array}$ & $32,4 \%$ & $48,8 \%$ & $13,6 \%$ & $5,2 \%$ \\
\hline 9. & $\begin{array}{l}\text { How o } \\
\text { intensi }\end{array}$ & $60,9 \%$ & $24,2 \%$ & $9,4 \%$ & \\
\hline 10. & $\mathrm{~d}$ taking breaks in the useof CTCTO equipment in your organization? & $22,4 \%$ & $47,3 \%$ & $24,5 \%$ & $5,8 \%$ \\
\hline 11. & How o & $9,1 \%$ & $33,9 \%$ & $37,0 \%$ & $20,0 \%$ \\
\hline 12. & How $\mathrm{c}$ & $13,0 \%$ & $30,6 \%$ & $39.4 \%$ & $17,0 \%$ \\
\hline 13. & & $39,1 \%$ & $48,2 \%$ & $10,0 \%$ & $2,7 \%$ \\
\hline 14. & $\begin{array}{l}\text { How of } \\
\text { in servi }\end{array}$ & $13,9 \%$ & $34,2 \%$ & $34,8 \%$ & $17,0 \%$ \\
\hline 15. & & $29,4 \%$ & $46,4 \%$ & $17,6 \%$ & $6,7 \%$ \\
\hline 16. & Hor & $7,3 \%$ & $26,1 \%$ & $48,8 \%$ & $17,9 \%$ \\
\hline 17. & $\begin{array}{l}\text { How often do you hide relationships withcolleagues from your organization through the use of CTCTO } \\
\text { technologies? }\end{array}$ & $77,3 \%$ & $17,9 \%$ & $2,4 \%$ & $2,4 \%$ \\
\hline & & & & $3,0 \%$ & \\
\hline & How often would you use CTCTO for personalcommunication if it is banned in the organization? & $58,5 \%$ & $30,6 \%$ & $6.7 \%$ & $4,2 \%$ \\
\hline
\end{tabular}

Table 2: Percentage Results per Response Option and by Item - EPLDDE Scale

\begin{tabular}{|l|l|c|c|c|c|}
\hline S. No. & Questions & $\mathbf{N}$ & $\mathbf{R}$ & $\mathbf{F}$ & $\mathbf{A}$ \\
\hline 1. & How often do employees use their particularCTCTO technology devices for organization services? & $1,0 \%$ & $17,7 \%$ & $50,0 \%$ & $31,3 \%$ \\
\hline 2. & How often do employees break the boundarybetween work and rest times regarding the use of CTCTO devices? & $5,2 \%$ & $30,2 \%$ & $44,8 \%$ & $19,8 \%$ \\
\hline 3. & $\begin{array}{l}\text { How often do employees appear dissatisfied withthe degree of freedom of use of the CTCTO granted by the } \\
\text { organization? }\end{array}$ & $17,7 \%$ & $53,1 \%$ & $21,9 \%$ & $7,3 \%$ \\
\hline 4. & How often do employees seem destabilized when CTCTO access restrictions are imposed on theorganization? & $15,6 \%$ & $34,4 \%$ & $36,5 \%$ & $13,5 \%$ \\
\hline 5. & $\begin{array}{l}\text { How often do employees prioritize their personalcommunication (Facebook, WhatsApp, and, .mail, etc ...) to } \\
\text { the detriment of work? }\end{array}$ & $15,6 \%$ & $54,2 \%$ & $26,0 \%$ & $4,2 \%$ \\
\hline 6. & How often do leaders in the organizationdisregard Digital Dependency as impacting on organizational dynamics? & $7,3 \%$ & $30,2 \%$ & $43,8 \%$ & $18,8 \%$ \\
\hline 7. & How often do leaders ignore employee characteristics that show evidence of DigitalDependence to CTCTO? & $9,4 \%$ & $29,2 \%$ & $39,6 \%$ & $21,9 \%$ \\
\hline 8. & $\begin{array}{l}\text { How often do leaders ignore their role ofidentifying and treating Digital Addiction to CTCTO in their areas of } \\
\text { expertise? }\end{array}$ & $9,4 \%$ & $24,0 \%$ & $40,6 \%$ & $26,0 \%$ \\
\hline 9. & $\begin{array}{l}\text { How often are interpersonal relationships negatively affected by the particular use of CTCTOtechnologies in } \\
\text { the organization? }\end{array}$ & $11,5 \%$ & $56,3 \%$ & $30,2 \%$ & $2,1 \%$ \\
\hline 10. & $\begin{array}{l}\text { How often do interpersonal relationships have been in the background in the organization, by theparticular use } \\
\text { of CTCTO technologies? }\end{array}$ & $15,6 \%$ & $54,2 \%$ & $29,2 \%$ & $1,0 \%$ \\
\hline
\end{tabular}




\begin{tabular}{|c|c|c|c|c|c|}
\hline 11. & How often do interpersonal relationships showless quality than the CTCTO digital alternative? & $11,5 \%$ & $54,2 \%$ & $33.3 \%$ & $1,0 \%$ \\
\hline 12. & How often do interpersonal relationships dependon the use of CTCTO in your organization? & $6,3 \%$ & $28,1 \%$ & $51,0 \%$ & $14,6 \%$ \\
\hline 13. & How often do interpersonal relationships compromise organizational results if not done byCTCTO technologies? & $12,5 \%$ & $49,0 \%$ & $30,2 \%$ & $8,3 \%$ \\
\hline 14. & How often does the organization increase theuse of CTCTO in the work? & $3,1 \%$ & $14,6 \%$ & $57,3 \%$ & $25,0 \%$ \\
\hline 15. & How often do organizational actions that maximize Digital Dependence occur as an incentiveto use CTCTOs? & $12,5 \%$ & $31,3 \%$ & $39,6 \%$ & $16,7 \%$ \\
\hline 16. & $\begin{array}{l}\text { How often are labor aspects disregardedregarding the use of CTCTOs of employees in activities of the } \\
\text { organization? }\end{array}$ & $17,7 \%$ & $34,4 \%$ & $30,2 \%$ & $17,7 \%$ \\
\hline 17. & How often are organizational results bad by theindiscriminate personal use of CTCTOs? & $22,9 \%$ & $57,3 \%$ & $18,8 \%$ & $1,0 \%$ \\
\hline
\end{tabular}

\section{Discussion}

Demographic data showed good frequency showing consistent degrees of instruction for comprehension of the scale, as well as good distribution of frequencies by age group. They offer satisfactory variability that minimizes the tendency of a predominant range, avoiding research bias.

Statistical analyzes demonstrated the adequacy of the two scales in terms of Bartlett's tests, KMO, factor loadings and internal consistency, qualifying the results.

The percentage results of the EDDE showed that, $73.6 \%$ of employees are not worried about digital access restrictions, answering question 1, which Never or Rarely destabilize with this, which may occur due to sure that restrictions will not occur.

In the second question, $89.4 \%$ corresponds to the sum of those who reveal that Never or Rarely prioritize their personal communication to the detriment of work. In 3, do not believe that their performances are affected by the excessive use of digital devices, totaling $88.2 \%$ the sum of answers Never and Rarely. In spite of this, [1] show that there is a commitment in personal, social, academic and professional life in volunteers with excessive use or dependence digital technologies.

Check e. mails at work after hours, $\log$ on to social networks or personal e. mails at work, increase connectivity, proliferate handheld devices use and can have negative consequences in personal and professional domains [11].

In the question $4,83.6 \%$ of volunteers, in the Never with Rare sum, do not care about restrictions on digital use. In 5, 90.3\% are not concerned with measures that minimize digital dependence, it seems that there is no problem in this regard.

Regarding the organization's lack of concern and improvement in income at work, there is a tie in questions 6 and 7 where $50 \%$ see concern and the other $50 \%$ do not. But yield can be affected as [12] report that through our evolutionary history, our cognitive system has been altered by the advent of technologies. With its multifaceted accessibility the Internet transforms behavior.

In questions 8,9 and 10 , there is coherence of the response percentages totaling respectively $81.2 \%, 85.1 \%$ and $69.7 \%$ of Never added to Rarely, for disregarding limits between normal and excessive use, dispensing intervals to alleviate the digital use and avoiding intervals of this use, demonstrating that they prioritize limits and rest of the digital. It is a great notice, because, in according to, negative impacts are created by the excessive use of the Internet affecting work and academic performance, family life, social relations, physical health and psychological well-being.

In relation to using their digital devices for labor services, the sum of Never with Rarely presented $43.7 \%$ while $56.3 \%$ of the sum of Frequently with Always states that this occurs, according to question 11. Similar equilibrium occurred in question 12 when asked about being more motivated by the organization's greater digital freedom. Of the total, $56.4 \%$ reveal, by the sum of Frequently and Always, that they feel more motivated by this. In question 13, the sum of Never with Rarely presented $87.3 \%$ on relationships with colleagues decreased by the use of digital devices, demonstrate that it does not happen among volunteers surveyed.

Regarding use of his particular devices at work, in question 14, a small majority with $51.9 \%$ of the Frequently with Always sum, says he feels comfortable with this permission. The effects of excessive use were also asked and answers Never added to Rarely presented $75.8 \%$ in question 15 stating that they do not disregard effects of excessive use of digital media which can signal awareness about their damages under these conditions.

From this perspective, according to [13] users of digital devices grow in a silent and worrying way. The adoption of new technologies and with the intensity of the access are changing people's way of life.

Corroborating results in the question $13,66.7 \%$ answered Frequently and Always, in the question 16, believing that they are better related due to digital resources, as [14] believes that this resource has dramatically changed the way we live and we find our way in the unknown territory, communicating efficiently, facilitating professional communications, promoting collaborative science with investigations around the world.

In demonstration of awareness of the volunteers, $95.2 \%$ and $93.3 \%$, represented by the sum of Never and Rarely, in the questions 17 and 18 respectively, do not hide their digital relationships from the organization and do not expect to receive messages of recognition. Reinforcing this awareness, $89.1 \%$ of the volunteers, in the question 19, from the Never with Rarely summed up, stated that they would not use their media in service if this practice was forbidden. 
Regarding EPLDDE, the question 1, answered by the leaders presented a percentage of $81.3 \%$ of responses revealing that employees use their particular devices in work activities, which may in the future lead to labor problems.

According to [5] digital dependence has grown in organizations without the perception of leaders, not prepared to identify and understand effects of this phenomenon, intervening in organizational human behavior and, consequently, culture, performance and results.

On breaking the boundary between work and rest times, $64.6 \%$ of the leaders in the question 2, say that this occurs, which can be detrimental to the performance and health of employees. On the other hand, $70.8 \%$ of the leaders, in the question 3, affirm that there is no dissatisfaction with the freedom granted for digital use, which is positive. In the question 4 , balance with $50 \%$ of the leaders for each side, about employees feel destabilized with digital access restrictions. About employees prioritizing their personal communications, $69.8 \%$ of the leaders affirm, in question 5 that it does not happen. This can be a good sign for organizational results. In 6, most leaders (62.6\%) believe that Often or Always disregard digital dependency as an impact on the organization, and may signal ignorance of the topic.

Despite these results, [11] says that distinctions between work and leisure, public and private, here and there, are rapidly disappearing, while the stress reported by the excessive use of digital technologies seems to be growing.

Similar percentages arise from the leaders in questions 7 and 8 , when asked about ignoring the digital dependence characteristics of their respondents $(61.5 \%)$ and their role of intervening in this context $(66.6 \%)$ corroborating the results of the question 6 . Also similar and relevant were the percentages generated by the leaders for questions 8, 10 and 11, respectively, $67.8 \%, 69.8 \%$ and $65.7 \%$ whenthey affirm that interpersonal relationships Never or Rarely suffer from using digital media, are second plan or lose quality for this, which is not $[15,16]$ perspective which reports that technology is the new answer to human isolation and alienation in modern society.

The question 12 reinforces these results when $65.6 \%$ of the leaders affirm that they depend on this type of communication. Despite this, $61.5 \%$ of the leaders answered in question 13 , that interpersonal relationships are not compromised if they are not done by digital devices. In the question 14, about the growth of device use in the organization, $82.3 \%$ of the leaders believe that it grows, corroborating [14] when this dependence is a global health issue. This feature has changed the way we live and found our way in the unknown territory, communicating with our friends and in professional communications. The question 15 presented a balance in responses when $56.3 \%$ of the leaders answered that Frequently or Always encourage digital use. One important aspect that is labor issues, in question $16,52.1 \%$ of the leaders think that labor aspects in the digital use of particular devices at work are not disregarded.
Finally, $80.2 \%$ of the leaders in question 17 , do not believe that the indiscriminate use of digital devices could harm organizational results, reinforcing results of the questions 8,10,11 and 12 .

\section{EDDE vs. EPLDDE Comparative Results}

Comparisons between the results of the two surveys provide elements for analyzing, as convergence or absence of them, for similar questions. These comparisons were made between questions from the EDDE and EPLDDE, with similar profiles, as described below.

Employees and leaders converge strongly on issue 12 (EPLDDE) and 16 (EDDE) when 65.6\% (leaders) and 66.7\% (employees) stated that they were better related to co-workers due to digital use. They differ strongly about employees using their particular devices for work (question 1 EPLDDE x 11 EDDE), because $81.3 \%$ of the leaders say they use it while $56.3 \%$ of employees admit this practice.

On breaking boundaries in working hours' $\mathrm{x}$ rest (question 2 EPLDDE x 8, 9 and 10 EDDE) $64.6 \%$ of leaders declare that it happens always or frequently. Employees, with low percentages $(18.8 \%, 14.9 \%$ and $30.3 \%)$ affirming practices similar to this, contradict the leaders with significant difference, deserving organizational analysis. As for digital use losses in results, question 17 EPLDDE presented $80.2 \%$ of leaders believing that Never or Rarely happens. Similarly, for employees, $46.6 \%$, in question 7 , believe that Always or Often their income improves with this use. Partially converge, when comparing question 3 (EPLDDE) on dissatisfaction with digital freedom with question 4 (EDDE), on concerns with organization restrictions to digital use. There is partial convergence because $70.8 \%$ of the leaders in question 3, Never or Rarely perceive dissatisfaction with this and in the question 4, $83.6 \%$ of employees assure that Never or Rarely worry about these restrictions. In question 5, do EPLDDE, 69.8\% of the leaders affirm that employees do not prioritize personal communication, while $89.4 \%$ of them affirm in question 2 that Never or Rarely prioritize their personal communication. Leaders do not believe that personal relationships are affected by digital use $(67.8 \%$ in the question 9 , $69.8 \%$ in 10 and $61.5 \%$ in 13 of the EPLDDE) while $87.3 \%$ of employees believe that these relationships do not decrease by digital use. Concerning partial disagreements, in question 4, EPLDDE, only half of the leaders do not see destabilization of employees with access restrictions, while in the question 1 of the EDDE, 73.6\% of employees Never or Rarely feel destabilized.

Regarding limitations, which did not harm the objectives the novelty of the theme stands out and some lack of knowledge on the part of the volunteers. As the application was in an organization, employees, even though they were told that the data would be treated collectively, may be mistrustful about the use of responses.

\section{Conclusion}

It is necessary to expand investigations about this phenomenon in organizations to direct the performance of their leaders in the better coexistence of teams with digital dependence. 
In this case it is possible to conclude that disagreements need to be treated as differentiated views between employees and leaders. It is possible to emphasize that they coexist peacefully with the labor use of particular digital devices. In addition, there is a demonstration that the two groups do not understand the extent of this dependence, and may therefore state in their answers that there is no such dependence.

The investigated organ was informed of the need to acculturate its teams of leaders and employees regarding the concepts and characteristics of digital dependence in function of the results of each group and the comparisons of results between similar questions of the two scales.

\section{Authors' Contribution}

L L Gonçalves: reviewed the literature, applied scales and wrote the article. A L S King: You have directed and written the article H K Santos: analyzed statistically and wrote the article. D Rodrigues: analyzed statistically and wrote the article. A E Nardi: Co guided and wrote the article.

\section{Conflict of Interests}

Authors declare that there are no conflicts of interest.

\section{References}

1. King ALS, Nardi AE (2014). Nomofobia - Computer addiction, internet, social networks? Cell Phone Dependence? Publisher Atheneu: Rio de Janeiro.

2. King ALS, Valença AM, Silva ACO, Baczynski T, Carvalho MR, et al (2012). Nomophobia: dependency on virtual environments or social phobia? Computers in Human Behavior 29: 1.

3. Johnson NF, Keane H (2017). Internet Addiction? Temporality and life on line in the network society. Time \& Society 26: 267-285.

4. Guedes E, Sancassiani F, Carta MG, CAMPOS C, Machado $\mathrm{S}$, et al. (2016). Internet addiction and excessive social networks use: what about facebook? Clinical Practice \& Epidemiology in Mental Health 12: 43-48.

5. Gonçalves LL (2017). Digital dependency: technologies transforming people, relationships and organizations. Rio de Janeiro: Editora Barra Livros.

6. Gonçalves LL (2014). Change Management in theory and practice and the Method of Management. São Paulo: Ed. All Print.

7. R Core Team (2017). R: A language and enviriment for statistical computing. R Foundation for Statistical Computing, Vienna, Austria, https:/www.R-project.org/

8. Dinno Alexis (2012). Paran: Horn`s Test of Principal Componentes/Factors. $\mathrm{R}$ package, version 1.5.1. https:// CRAN.R-project.org/package $=$ paran.

9. Falissard Bruno (2012). Psy: Various procedures used in psychometry. R package version 1.1. https://CRAN. R-project. org/package $=$ psy.
10. Wickham H, Francois R, Henry L, Müller K (2017). Dplyr: A Grammar of Data manipulation. R Package version 0.7.4. https://CRAN. R-project.org/package=dplyr.

11. Scott DA, Valley B, Simecka BA (2017). Mental Health Concerns in the Digital Age. International Journal of Mental Health and Addiction 15: 604-613.

12. Loh HK, Kannai R (2016). How has the Internet Reshaped Human Cognition? Neurocientist 22: 506-520.

13. King ALS, Padua MK, Guedes E, Nardi AE (2018). Digital Ergonomics. Porto Alegre: EducaBooks.

14. Montag C, Sindermann C, Becker B, Pank SJ (2016). An Affective Neuroscience Framework for the Molecular Study of Internet Addiction. Front Psychology 2016: 7.

15. Kass AS (2014) Hidden retalting: The world of online support. Review of the book The Paradox Internet Groups: Alone in the Presence of Virtual Others. H. Weinberg. Psycritiques, 2014: 59.

16. Shek RCF (2018). Prerenting and combating Internet addiction: A concept review. In LEE, TY; SHEK, RCF; SIN, RCF. Qiality of Life in Asia. P.71-79. New York. Ny: Springer Science Business Medical.

Copyright: (02020 Lucio Lage Gonçalves, et al. This is an open-access article distributed under the terms of the Creative Commons Attribution License, which permits unrestricted use, distribution, and reproduction in any medium, provided the original author and source are credited. 